\title{
O FILME DE ANIMAÇÃO COMO RECURSO DIDÁTICO NAS AULAS DE CIÊNCIAS
}

José Nunes dos Santos ${ }^{1}$, Cibele Fronzoi Silva Souza ${ }^{2}$, Maria José Fontana Gebara ${ }^{3}$

${ }^{1}$ Universidade Estadual de Campinas - UNICAMP, Doutorando/PECIM, Campinas, SP. ${ }^{2}$ Universidade Estadual de Maringá - UEM, Mestranda/PCM, Maringá, PR. ${ }^{3}$ Universidade Federal de São Carlos - UFSCar, Docente, Sorocaba, SP. E-mail: nunesvi@hotmail.com

\section{RESUMO}

O uso de filmes em sala de aula deve estar alicerçado no planejamento de ensino. Para correta utilização, sugere-se que o docente identifique os conceitos científicos presentes no enredo, certificando-se que os mesmos não apresentem falhas conceituais, comumentemente encontradas nos gêneros de animação. Nesse artigo, apresentamos o resultado de uma analise do filme "Procurando Nemo" como recurso didático para o processo de ensino e aprendizagem de Ciências, com o objetivo de identificar fragmentos do enredo fílmico que possibilitem a construção de conceitos científicos de Biologia, Física e Química. Os dados foram colhidos através da análise de fragmentos do enredo fílmico. A pesquisa teve natureza qualitativa, ancorada na análise de imagens e do enredo que compõem o filme. O filme possibilita discutir conceitos básicos de Ecologia. Contudo, a ficção científica trabalha com um mundo imaginário, motivo pelo qual os filmes podem proporcionar uma visão incorreta do ponto de vista científico.

Palavras-chave: Filme de animação. Fragmentos fílmicos. Ensino de ciências naturais. Conceitos científicos. Apropriação do conhecimento

\section{THE ANIMATION MOVIE AS A TEACHING RESOURCE IN SCIENCE CLASS}

\begin{abstract}
The use of movies in the classroom must be grounded in educational planning. For correct use, the teacher is suggested to identify the scientific concepts existent in the plot, making sure that they do not present conceptual flaws, commonly found in the animation genre. In this article, we present the result of the movie's analysis"Finding Nemo" as a teaching resource to the teaching process and Science's learning, in order to identify filmic plot fragments that allow the construction of scientific concepts from Biology, Physics and Chemistry. Data were collected through the filmic plot fragment analysis. The nature of the research was qualitative, anchored in the image and plot analysis that make up the movie. The movie allows discuss basic concepts of ecology. However, science fiction works with an imaginary world, the reason why the movies can provide an incorrect view of the scientific point of view.
\end{abstract}

Keywords: Animated movies. Filmic fragments. Teaching Science's learning. Scientific concepts. Appropriation of knowledge. 
INTRODUÇÃO

Embora figura fundamental no processo educativo, o professor não se constitui como a única fonte de informações para a construção/apropriação do conhecimento escolar. Sendo assim, as instituições escolares, frente às transformações tecnológicas, devem buscar a reestruturação de recursos pedagógicos que possam contribuir para a formação do aluno. A admissão de recursos tecnológicos, como o filme, pode, além de tornar as aulas mais prazerosas, tornar-se um importante aliado nas aulas de Ciências Naturais.

De acordo com Santos (2011, p. 44), "recursos pedagógicos são todos os elementos que contribuem para a aprendizagem do aluno". Partindo desse pressuposto, o ensino de Ciências Naturais pode ser reorganizado por meio de uma prática que, ao abranger diversas metodologias, possibilite a construção do conhecimento escolar. Nessa perspectiva, o filme do gênero de animação é um recurso pedagógico mediador, que auxilia o ensino por meio da problematização, em diferentes conteúdos relacionados às Ciências Naturais, possibilitando que se estabeleça o diálogo entre diferentes disciplinas e o conhecimento escolar.

Na concepção de Napolitano (2010), os diferentes elementos presentes nos filmes, tais como o conteúdo, a linhagem ou a técnica, podem ser utilizados na sala de aula. Sua utilização, para a abordagem de um conteúdo, abrange a fonte e o texto gerador. O filme, como fonte, permite a análise de um problema e o esclarecimento de dúvidas apresentadas por parte dos alunos, as quais surgem a partir da narrativa da obra; enquanto que o filme, como texto gerador, aponta para uma mediação limitada, em que o professor tem menos compromisso com o filme em si, sua linguagem, sua estrutura e os temas que suscita.

O filme não deve ser utilizado no contexto escolar como simples ilustração, mas sim, como forma de promover uma análise crítica da narrativa e das representações fílmicas, consideradas elementos propulsores de pesquisas e debates temáticos, promovendo a articulação currículo/conteúdo, habilidades e conceitos que são categorias básicas da relação de ensino-aprendizagem escolar.

Para Napolitano (2010), tais categorias se atrelam ao uso de filmes da seguinte forma: o conteúdo curricular pode ser abordado por meio de temas provenientes das diversas disciplinas que formam a matriz curricular; habilidades e competências possibilitam um trabalho articulado com a leitura e a elaboração de texto; os conceitos presentes nos argumentos dos filmes podem proporcionar debates acerca dos problemas sugeridos.

Essas possibilidades norteiam uma reflexão prévia sobre os objetivos que o professor pretende atingir por meio das atividades relacionadas ao filme. Ao escolher um filme, convém 
ao professor não esquecer que o mesmo pode, direta ou indiretamente, mostrar determinado conteúdo científico.

Este artigo apresenta uma sucinta apreciação do filme "Procurando Nemo" e tem como objetivo identificar fragmentos do enredo que possibilitem a construção/apropriação de conceitos científicos de Ciências Naturais.

\section{METODOLOGIA}

Para a realização desse artigo, analisou-se o filme de animação, intitulado "Procurando Nemo", com o propósito de gerar reflexões acerca da importância e dos subsídios ao processo de planejamento do ensino de Ciências Naturais, com o intuito de discutir que o uso de filmes em sala de aula, além de trazer encanto ao conhecimento escolar, deve estar, fortemente, alicerçado no ensino.

A pesquisa, de natureza qualitativa, procurou colher saberes sobre as representações do enredo fílmico (o que contam e representam as personagens), ideias principais do filme; articulação com o conhecimento escolar (conteúdo básico e conteúdo específico); conceitos errôneos transmitidos pelo gênero de animação. Tal análise foi possível, pois a investigação qualitativa em educação possibilita estudar uma situação natural, coletar dados descritivos e investigar a realidade de forma contextualizada (LÜDKE; ANDRÉ, 1986).

Desta forma, desenvolveu-se uma pesquisa com a intenção de responder às seguintes questões: Há fragmentos do enredo fílmico que podem ser separados e expostos para encantar e subsidiar o alunado na construção/apropriação de conceitos científicos? Há erros morfológicos nos animais presentes no filme? Há formulações de conceitos errados de Biologia, Física e Química no enredo fílmico?

$\mathrm{Na}$ procura de respostas para esses questionamentos, foram detalhados fragmentos do enredo fílmico, os quais foram apresentados como recursos pedagógicos e como subsídios para a aprendizagem, bem como evidenciar eventuais conceitos errôneos difundidos pela ficção.

\section{DISCUSSÃO}

A escolha de um filme para abordar determinado conteúdo escolar implica, na desconstrução, identificação e discriminação dos elementos que compõem o seu conjunto, bem como, a articulação com o tema trabalhado em sala de aula. O filme "Procurando Nemo" (2003) é uma animação, criada pelos estúdios Disney e Pixar; com duração de uma hora e quarenta minutos; direção de Andrew Stanton e Lee Unkrich. O desenho narra a história de dois peixes- 
palhaço, Marlin e Nemo, pai e filho, respectivamente. No filme, destacam-se temas relacionados ao comportamento da biodiversidade marinha e terrestre, bem como questões relativas à filosofia, à força de vontade, à confiança, à amizade e à capacidade de superar/enfrentar medos.

O desenho pode ser assistido por estudantes de toda a educação básica e permite abordar temas disciplinares e interdisciplinares relacionados a fenômenos científicos. No caso do ensino de Ciências Naturais, "Procurando Nemo" permite que o professor explore, por exemplo, as relações ecológicas do mundo da biologia marinha: cadeia alimentar, ecossistemas, biomas e inter-relações entre os seres vivos e seus ambientes físicos.

Nemo, personagem-título do filme, é um peixe-palhaço que perdeu a mãe e os irmãos, ainda em fase de desenvolvimento dentro do ovo, isto é, em período de incubação. A fatalidade acontece durante um violento ataque de um peixe barracuda. Da agressão, resiste apenas um ovo, que virá a ser o personagem Nemo.

A taxonomia biológica classifica os peixes-palhaço como ovíparos, pois os filhotes se desenvolvem fora do corpo da mãe, dentro do ovo, que contém os nutrientes necessários. Mais de $90 \%$ dos peixes pertencem a essa categoria. Peixes femininos ovíparos põem seus ovos não fertilizados sobre uma superfície de rocha ou planta, os quais podem ser fertilizados pelo macho, ao friccionar seus órgãos sexuais nos ovos, soltando seu esperma, ou, ainda, ao lançar seu esperma na água de maneira que a fecundação aconteça no zooplâncton. Essas espécies de peixe reproduzem várias vezes durante $o$ ano.

$\mathrm{Na}$ biodiversidade marinha há uma variedade de peixes-palhaço, destacando-se dentre outros, os Anisotremus virginicus, Bodianus rufus, Pomacanthus arcuatus, Pomacanthus paru, Gobiosoma oceanops, Centropristes melanus e Dascyllus trimaculatus, Amphiprion ocellaris (HOFF, 1996). Nessas espécies, todos os peixes ao nascerem são todos machos, com o acondicionamento de tornarem-se fêmeas conforme a necessidade da colônia, ou seja, a dimensão e a taxa de crescimento são acertados de acordo com a sua posição social na hierarquia (BUSTON, 2003).

A transformação de machos em fêmeas ocorre devido ao processo hormonal e, de acordo com Buston (2003), essa característica é denominada hermafroditismo protândrico. Na natureza, a transformação de um macho ativo em fêmea, ou de macho imaturo em macho maturo, pode demorar alguns meses ou até anos (HOFF, 1996). No ambiente marinho, principalmente entre as anêmonas (animal invertebrado), é possível encontrar pares formados de macho e fêmea que permanecem unidos durante toda a vida e defendem ferozmente o seu território. 
Retomando o enredo fílmico, Marlin, o pai de Nemo, tem uma vida traumatizada pelos perigos do mar e desde o acidente com sua esposa habituou-se a proteger o filho dos predadores, impedindo-o de fazer qualquer coisa. Perturbado e repleto de tiques nervosos, devido a alienações geradas pelo medo, Marlin se torna um peixe frustrado e com pouca aspiração por inovações, chegando, inclusive, a evitar que o filho frequente a escola de peixes, onde as aulas são ministradas por um peixe raia. As raias, arraias ou peixes batóides são peixes cartilaginosos (Chondrichthyes) marinhos, classificados na subclasse Elasmobranchii.

No primeiro dia de aula, após uma discussão, Nemo nada rumo ao mar aberto, desobedecendo seu pai. Na tentativa de provar ao pai que tem a maturidade suficiente para desafiar os perigos marítimos, o pequeno peixe é capturado por um mergulhador, que o leva para um aquário, no consultório de um dentista, com vista para a Baía de Sydeny. Nesse aquário, Nemo entra em contato com diversas espécies, que foram capturadas no mar e vendidos em pet shops (lojas de animais).

Desesperado, Marlin empreende uma jornada, atravessando todo o mar da Austrália para salvar o filho. Nesse percurso, ele se coloca frente aos perigos que o mar lhe oferece, encarando o medo que tem do oceano. Em sua busca, ao passar por um cardume, conhece Dory, um peixe fêmea que sofre de "perda de memória recente", um tipo de amnésia. Trata-se de uma personagem motivadora, que constitui um estímulo necessário e categórico para Marlin não desistir de reencontrar o filho. Juntos, eles partem para a difícil missão da procura por Nemo.

Enfrentando o oceano, Marlin e Dory procuram o pequeno peixe. Nessa difícil jornada, ambos encontram tubarões que não comem peixes, momento que constitui uma cena divertida, ainda que trágica para a natureza, a luta desses tubarões contra a vontade de consumir peixe. A dupla também encontra tartarugas surfistas e até uma baleia aparece no percurso, enquanto arriscam chegar à cidade de Sydney, onde Nemo foi movido.

Tubarões são peixes cartilaginosos (Chondrichthyes) marinhos, classificados na subclasse Elasmobranchii (a mesma das arraias), da Super ordem Selachimorpha - são carnívoros e costumam se alimentar de peixes, crustáceos, lulas, polvos, tartarugas, raias e outros cações (AMABIS; MARTHO, 2010). Por sua vez, tartarugas marinham são répteis que vivem nos oceanos, em áreas tropicais e subtropicais. Esses répteis se alimentam, principalmente, de medusas, camarões, esponjas e águas-vivas (AMABIS; MARTHO, 2010). As baleias classificam-se como mamíferos marítimos pertencentes à ordem dos Cetáceos e são animais que, desde o nascimento até a morte, vivem na água; não têm guelras e, por isso, periodicamente, têm de subir para respirar na superfície, (AMABIS; MARTHO, 2010). 
No enredo fílmico, Marlin e Dory obtêm sucesso na sua empreitada e o "boca-a-boca" sobre essa dupla espetacular se dissemina, não apenas na biodiversidade marinha, mas também entre as aves. Tamanha notoriedade, faz com que o rumor chegue até Nemo, que descobre que seu pai está a sua busca. Enquanto isso, Nemo e o companheiro Gil, um peixe ídolo mourisco, planejam uma estratégia para fugir do aquário. Animado por Gil - chefe da turma do aquário - e determinado pelo anseio de voltar ao encontro do pai, Nemo e a turma põem em atuação o plano de fuga. Porém, Nemo tem pouco tempo, pois Darla, sobrinha do dentista, uma menina tenebrosa conhecida por torturar animais, principalmente peixes, está prestes a chegar para levar Nemo para casa como bichinho de estimação.

Marlin e Dory, ao chegar ao porto de Sydney, contam com a ajuda de Nigel, um simpático pelicano impressionado pela coragem do peixe-palhaço para encontrar seu filho. Enquanto Nemo executa seu plano de fuga, Darla chega para buscá-lo e coloca o peixinho em um saco plástico para leva-lo para casa. Enquanto isso, o pai de Nemo e Dory chegam ao consultório carregados pelo pelicano. Nesse momento, inicia-se uma grande confusão entre Darla, o dentista e o pelicano e o saco plástico onde estava Nemo, cai na pia e vai parar no esgoto, rumo ao mar. Nigel, o pelicano, retorna com Marlin e Dory para o mar e, finalmente, depois de muitos obstáculos, pai e filho conseguem se reencontrar.

O filme é uma maneira lúdica de apresentar aos alunos questões relativas a alguns conceitos básicos de Ecologia, como, por exemplo, população biológica; comunidade biológica; ecossistema; nicho ecológico; habitat; relações ecológicas etc.. Além disso, o filme possibilita discutir o funcionamento de um ecossistema, que resulta da interação entre seus componentes bióticos (seres vivos) e seus componentes abióticos (fatores físicos e químicos).

A ecologia é uma Ciência importante no contexto escolar, pois permite uma atitude interdisciplinar e multidisciplinar que pode envolver outras áreas de estudos, como, a Filosofia; a Geografia; a Química; a Física; a Sociologia; a Economia entre outras. Estudar conceitos de Ecologia permite compreender alguns processos, isto é, relações ecológicas que possibilitam a vida no planeta Terra.

Um fato importante do filme é a amizade que nasce entre Marvin e Dory, embora desiguais. Tais desigualdades colaboraram para que eles pudessem vencer os desafios que lhes foram apresentados na vida marinha.

Contudo, convém lembrar que a ficção científica trabalha com um mundo imaginário, que pode contradizer a realidade, motivo pelo qual os filmes podem proporcionar uma visão incorreta do ponto de vista científico. Alguns exemplos podem ser observados no Quadro 1. 
Quadro1. Relação de alguns conceitos errados presentes no filme "Procurando Nemo"

\begin{tabular}{|l|l|}
\hline \multicolumn{1}{|c|}{ Conceitos errados presentes no filme } & \multicolumn{1}{|c|}{ Conceitos corretos } \\
\hline Tubarões que não comem peixes. & $\begin{array}{l}\text { Tubarões são carnívoros e costumam se } \\
\text { alimentar de peixes }\end{array}$ \\
\hline $\begin{array}{l}\text { Barracuda se alimenta de peixes-palhaço e e } \\
\text { de seus ovos. }\end{array}$ & $\begin{array}{l}\text { A barracuda se alimenta de peixes, como, } \\
\text { garoupas, pargos, pequenos atuns, tainhas, } \\
\text { arenques e anchovas. }\end{array}$ \\
\hline $\begin{array}{l}\text { A água da pia do consultório dentário roda } \\
\text { em sentido anti-horário, como no hemisfério } \\
\text { norte. }\end{array}$ & $\begin{array}{l}\text { Considerando que o filme se passa na Austrália, } \\
\text { no hemisfério sul, portanto, a água deveria } \\
\text { rodar em sentido horário. }\end{array}$ \\
\hline Os peixes do filme apresentam pálpebras. & Peixes não têm pálpebras. \\
\hline Os peixes do filme possuem olhos frontais & Os peixes apresentam olhos nas laterais. \\
\hline
\end{tabular}

Fonte: Autoria própria

Tais questões precisam ser advertidas durante os debates realizados com os alunos, mas as mesmas não interferem nas possibilidades de o filme despertar o empenho dos estudantes para o aprendizado de conhecimentos escolares.

\section{CONSIDERAÇOES FINAIS}

No filme de animação "Procurando Nemo", o telespectador/aluno pode se apropriar dos elementos fílmicos, como as imagens e os movimentos sonorizados, entre outros, os quais auxiliam na construção de significados que visam à construção do conhecimento científico.

Para Santos (2013, p. 62), “O filme como recurso pedagógico permite ao aluno a apropriação de conhecimentos científicos, capazes de propiciar situações de troca para que possa estabelecer relações entre o estudo do científico e a realidade". É fato que filme não supre a mediação do professor, mas sugere uma leitura reflexiva de determinado assunto e contexto, mediante sua linguagem, sua manifestação cultural, bem como, permite a construção do conhecimento escolar.

A prática do uso de filmes em sala de aula precisa estar alicerçada no planejamento de ensino. Sugere-se, pois, que o docente assista previamente aos filmes com a finalidade de constatar conceitos científicos presentes no enredo, uma vez que estes podem apresentar falhas conceituais, comumentemente encontradas nos gêneros de animação.

Aqui, há que se levar em consideração o fato de que o autor, ao elaborar o roteiro fílmico de animação comercial, não está comprometido com o desenvolvimento de um filme de gênero educativo, tendo, portanto, liberdade de não se ater à realidade científica, daí o caráter ficcional do gênero. Nessas produções, alguns detalhes podem passar despercebidos a um olhar menos 
cauteloso para os conceitos científicos. Assim, os professores que lançarem mão desse recurso no processo educacional, além de empregar as representações reais que esses filmes proporcionam, podem trabalhar, também, tais erros em sala de aula, relacionando-os com o que almejam focar.

\section{REFERÊNCIAS}

AMABIS, José M; MARTHO, Gilberto R. Biologia dos organismos. 3. ed. São Paulo: Moderna, 2010.

BUSTON, P. Size and growth modification in clownfish. Nature. Londres: Nature, 2003, 424(1): 145-146. http://dx.doi.org/10.1038/424145a

HOFF, F. H. Conditioning, spawning and rearing of fish with emphasis on marine clownfish. Florida: Aquaculture Consultants Inc., 1996, 120p.

LASSETER, J (Produtor), STANTON, A E UNKRICH, L. (Diretores). Procurando Nemo. [Filme]. Estados Unidos: Walt Disney \& Pixar, 2003.

LÜDKE, M.; ANDRÉ, M. Pesquisa em educação: abordagens qualitativas. São Paulo: EPU, 1986.

NAPOLITANO, Marcos. Como usar o cinema na sala de aula. São Paulo: Contexto, 2010.

SANTOS, J. N. dos. $O$ ensino-aprendizagem de Ciências naturais na educação básica: o filme como recurso didático nas aulas de Ecologia. 2013. 272 p. Dissertação (Mestrado Profissional em Formação Científica, Educacional e Tecnológica) - Programa de Pós-Graduação em Formação Científica, Educacional e Tecnológica - PPGFCET, Universidade Tecnológica Federal do Paraná UTFPR. Curitiba, 2013.

SANTOS, J. N. dos. Ensinar ciências. Reflexões sobre prática pedagógica no contexto educacional. Blumenau: Nova letra, 2011. 